\title{
PENGARUH MARKETING MIX TERHADAP LOYALITAS PELANGGAN DI WARUNG MAKAN TIP TOP KELURAHAN SAOMBO KECAMATAN GUNUNGSITOLI KOTA GUNUNGSITOLI
}

\author{
Peringatan Harefa \\ STIE Pembangunan Nasional \\ peringatan.har@gmail.com
}

\begin{abstract}
Abstrak
In this study, the formulation of the problem "Is there an Effect of Marketing Mix on Customer Loyalty in TIP TOP Restaurant, Saombo Village, Gunungsitoli District, Gunungsitoli City?". This research aims: a. to find out and obtain data about the implementation of the marketing mix carried out at the TIP TOP Restaurant, Saombo Village, Gunungsitoli District, Gunungsitoli City. b. to find out and obtain data about customer loyalty at TIP TOP Restaurant, Saombo Village, Gunungsitoli District, Gunungsitoli City. c. to find out how much influence the marketing mix has on customer loyalty at the TIP TOP Restaurant, Saombo Village, Gunungsitoli District, Gunungsitoli City.The sample in this study was taken from the entire population of 97 people, the method used in this research is quantitative research methods (Inferest), where the data collected is verified, validated, and tested for the hypothesis using the t test. Processing data distribution $t$ with $d k=95$ and a significant level of $5 \%$ obtained t table $=1.661$. Thus, $t_{\text {count }}>t_{\text {table }}(10.626>1.661)$, with a correlation coefficient of 0.737 . The results obtained by testing the coefficient of determination are $54 \%$, the effect of the marketing mix on customer loyalty, while other factors that are not discussed in this study are $46 \%$. Based on the results of hypothesis testing, $H a$ is accepted and Ho is rejected, indicating that $t_{\text {count }}>t_{\text {table }}(10.626>1.661)$, so it can be said that there is an effect of marketing mix on customer loyalty at TIP TOP Restaurant, Saombo Village, Gunungsitoli District, Gunungsitoli City.
\end{abstract}

Kata Kunci Marketing Mix with Customer Loyalty.

\section{PENDAHULUAN}

Perkembangan teknologi pada era globalisasi dimanfaatkan oleh para pengusaha untuk memperkenalkan usahanya seperti usaha di bidang warung makan. Pemanfaatan teknologi dan informasi dapat mendukung kemajuan bisnis, salah satunya untuk mempromosikan produk. Penggunaan teknologi membuat gaya hidup masyarakat kota menjadi semakin kompleks. Hal ini dapat dilihat dari gaya hidup masyarakat kota yang semakin bervariasi. Salah satunya adalah menghabiskan waktu sambil bercengkraman menikmati makanan kecil dan minuman di sebuah warung makan sudah menjadi trend di masa sekarang ini khususnya di Kota Gunungsitoli.

Jumlah warung makan yang banyak membuat tingkat persaingan yang semakin ketat mengakibatkan konsumen memiliki posisi tawar yang tinggi terhadap kualitas produk, harga produk, lokasi yang strategis, serta promosi yang ditawarkan oleh sebuah warung makan. Saat ini kompetisi pada usaha di bidang warung makan tidak hanya pada produk, namun menyangkut variabel lain yang berkaitan dengan nilai atas pengalaman berbelanja konsumen.

Nilai ini berkaitan dengan bagaimana suatu perusahaan dapat memahami keinginan dan kebutuhan konsumen sehingga dapat menentukan strategi pemasaran. Strategi pemasaran yang tepat merupakan hal penting yang dapat mendukung pelaku bisnis untuk mampu bersaing dengan pesaingnya, sehingga hal tersebut dapat meningkatkan keunggulan kompetitif yang berkelanjutan serta dapat memuaskan keinginan konsumen, dengan demikian tujuan dari perusahaan tersebut dapat tercapai.

Hal ini tercermin dari banyaknya pengusaha yang menyertakan komitmennya terhadap loyalitas pelanggan. Kunci utama perusahaan untuk memenangkan persaingan adalah dengan memberikan kepuasan kepada pelanggan melalui kualitas produk yang baik, harga yang bersaing, lokasi yang strategis serta promosi yang tinggi. 
Menurut Tjiptono (2008: 110), menyatakan loyalitas pelanggan sebagai komitmen pelanggan terhadap suatu merek, toko, pemasok berdasarkan sikap yang sangat positif dan tercermin dalam pembelian ulang yang konsisten".

Berdasarkan pengalaman yang diperoleh, pelanggan memiliki kecenderungan untuk membangun nilai-nilai tertentu. Nilai ini yang akan membuat pelanggan untuk melakukan perbandingan terhadap produk dan jasa yang pernah ditawarkan. Apabila sebuah warung makan memberikan produk atau jasa yang berkualitas baik, maka diharapkan dapat memenuhi harapan pelanggan dan akhirnya mampu memberikan nilai yang maksimal serta menciptakan kepuasan bagi pelanggan.

Menurut Kotler \& Keller (2000: 177), bahwa kepuasan konsumen adalah perasaan senang atau kecewa seseorang yang muncul setelah membandingkan hasil produk yang dipikirkan terhadap kinerja yang diharapkan terciptanya kepuasan pelanggan dapat memberikan beberapa manfaat diantaranya hubungan antara perusahaan dan pelanggannya menjadi harmonis, memberikan dasar yang baik bagi pembelian ulang dan terciptanya loyalitas pelanggan".

Loyalitas diharapkan agar pengusaha mendapatkan keuntungan jangka panjang atas hubungan mutualisme yang terjalin dalam kurun waktu tertentu. Hal inilah yang membuat para pengusaha khususnya pada bidang warung makan berlomba-lomba untuk menjaga loyalitas pelanggan agar tidak beralih ke pesaing lain. Salah satunya yaitu warung makan TIP TOP Kelurahan Saombo Kecamatan Gunungsitoli Kota Gunungsitoli, dapat menikmati makanan seperti tahu isi, mie goreng, mie balap, nasi goreng yang bervarian rasa, kopi dan minuman dingin dan panas, dapat menjadikan pelanggan loyal dengan produk hidangannya yang khas.

\section{LANDASAN TEORI}

\section{Pengertian Marketing Mix}

Menurut Chaffey (2009: 449), Marketing Mix adalah sekumpulan alat strategi pemasaran yang terkontrol yang ada di perusahaan untuk mendapatkan respon dari target pasar. Marketing Mix meliputi apa saja yang dapat di lakukan perusahaan untuk mempengaruhi permintaan untuk produknya.

Sedangkan menurut Kartajaya (2006: 18), Marketing Mix merupakan taktik untuk mengintegrasikan tawaran, logistik dan komunikasi produk atau jasa. Hal ini penting karena Marketing Mix merupakan aspek yang paling terlihat (tangible) dari sebuah perusahaan dalam aktivitas pemasaran.

Berdasarkan pendapat di atas dapat dijelaskan bahwa Marketing Mix merupakan strategi yang dipergunakan oleh perusahaan dalam mempengaruhi permintaan atas produk kepada pelanggan sehingga pelanggan tidak mudah meninggalkan produk dari perusahaan dan tetap melakukan pembelian terhadap produk yang ditawarkannya.

\section{Konsep Pemasaran}

Pemasaran merupakan salah satu kegiatan yang dilakukan oleh perusahaan dalam usaha mencapai tujuan perusahaan yaitu mempertahankan kelangsungan hidup dan mendapatkan laba yang maksimum. Berhasil tidaknya mencapai tujuan tersebut tergantung dari keahlian mereka di bidang pemasaran, produksi dan bidang-bidang lain yang menunjang tercapainya tujuan tersebut.

Menurut Kotler \& Armstrong (2001: 7), pemasaran adalah suatu "proses sosial dan manajerial yang membuat individu dan kelompok memperoleh apa yang mereka butuhkan dan inginkan lewat penciptaan dan pertukaran timbal balik produk dan nilai dengan orang lain".

Selanjutnya Swasta \& Irawan (2000: 5), menyatakan bahwa pemasaran adalah suatu sistem dari kegiatan bisnis yang ditujukan untuk merencanakan, menentukan harga, mempromosikan dan mendistribusikan barang dan jasa yang dapat memuaskan kebutuhan baik dari pembeli yang ada maupun pembeli potensial".

Berdasarkan definisi di atas, maka perusahaan mempunyai peranan penting dalam membangkitkan era kegiatan ekonomi dan standar hidup yang baru. Konsep pemasaran dimulai dari sasaran perusahaan, kebutuhan dan keinginan konsumen yang terpadu dan terkoordinir dimana semua kegiatan akan mempengaruhi kepuasan pelanggan.

Menurut Tjiptono (2008: 22), Konsep pemasaran (marketing concept) berpandangan bahwa kunci untuk mewujudkan tujuan organisasi terletak pada kemampuan organisasi dalam menciptakan, memberikan dan mengkomunikasikan nilai pelanggan (costumer value) kepada pasar sasarannya secara lebih efektif dibandingkan pada pesaing. Tujuan akhir pemasaran adalah membantu organisasi mencapai tujuannya. Tujuan utama dalam perusahaan adalah mencari laba. Sedangkan tujuan lainnya adalah mendapatkan dana yang memadai untuk melakukan aktivitas-aktivitas sosial dan pelayanan publik.

Konsep pemasaran menekankan orientasi pada kebutuhan dan keinginan konsumen yang didukung oleh kegiatan pemasaran terpadu, yang ditujukan untuk menciptakan kepuasan langganan sebagai kunci 
untuk keberhasilan mencapai tujuan perusahaan. Dengan demikian ada empat unsur pokok yang terdapat dalam konsep pemasaran, yaitu: orientasi pada konsumen (kebutuhan dan keinginan konsumen), kegiatan pemasaran yang terpadu, kepuasan konsumen/langganan dan tujuan perusahaan jangka panjang.

\section{Bauran Pemasaran}

Pemasaran biasanya mengunakan sejumlah alat untuk mendapatkan tanggapan yang diinginkan dari pasar sasaran. Bauran Pemasaran (Marketing mix) merupakan salah satu konsep utama dalam pemasaran modern, strategi pemasaran dimulai dengan melakukan segmentasi pasar, analisis lingkungan, seleksi pasar untuk segmentasi pasar dan pengembangan bauran pemasaran.

Menurut Kotler (2002: 18), bauran pemasaran adalah sekumpulan alat pemasaran yang dapat digunakan oleh perusahaan untuk mencapai tujuan pemasarannya dalam pasar sasaran.

Sedangkan menurut Saladin \& Oesman (2002: 3), bauran pemasaran adalah serangkaian dari variabel pemasaran yang dapat dikuasai oleh perusahaan dan digunakan untuk mencapai tujuan dalam pasar sasaran.

Kotler \& Armstrong (2001: 71), "bauran pemasaran sebagai perangkat alat pemasaran taktis dan terkontrol yang dipadukan oleh perusahaan untuk menghasilkan respon yang diinginkan pasar sasaran. Bauran pemasaran terdiri atas segala sesuatu yang dapat dilakukan perusahaan untuk mempengaruhi permintaan produknya. Kemungkinan kemungkinan itu dapat dikelompokkan menjadi empat kelompok variabel yang dikenal dengan "Empat P": product, price, place dan promotion (produk, harga, lokasi dan promosi)".

\section{Loyalitas Pelanggan}

Secara harfiah, loyal berarti setia, sehingga loyalitas diartikan sebagai kesetiaan yang timbul tanpa adanya paksaan, tetapi timbul dari kesadaran sendiri. Kesetiaan ini timbul tanpa adanya paksaan tumbuh dengan sendirinya. Pada masa lalu usaha untuk menciptakan kepuasan pelanggan lebih cenderung mempengaruhi sikap, sebaliknya loyalitas pelanggan lebih menekankan perilaku membeli.

Oliver (dalam Kotler \& Keller, 2009: 138), mendefinisikan "loyalitas (loyalty) sebagai komitmen yang dipegang secara mendalam untuk membeli atau mendukung kembali produk atau jasa yang disukai di masa depan meski pengaruh situasi dan usaha pemasaran berpotensi menyebabkan pelanggan beralih".

Menurut Sheth \& Mital (dalam Tjiptono, 2010: 393), "Loyalitas pelanggan adalah komitmen pelanggan terhadap suatu merek, toko atau pemasok, berdasarkan sikap yang sangat positif dan tercermin dalam pembelian ulang yang konsisten".

\section{Hipotesis}

Menurut Sugiyono (2010: 93), bahwa "Hipotesis merupakan jawaban sementara terhadap rumusan masalah penelitian, oleh karena itu rumusan masalah penelitian biasanya disusun dalam bentuk kalimat pertanyaan". Berdasarkan pendapat di atas maka penulis merumuskan hipotesis penelitian ini yaitu:

$\mathrm{Ha}$ : Ada pengaruh marketing mix terhadap loyalitas pelanggan di Warung Makan TIP TOP Kelurahan Saombo Kecamatan Gunungsitoli Kota Gunungsitoli.

Ho : Tidak ada pengaruh pengaruh marketing mix terhadap loyalitas pelanggan di Warung Makan TIP TOP Kelurahan Saombo Kecamatan Gunungsitoli Kota Gunungsitoli.

\section{METODOLOGI PENELITIAN \\ Data}

Di dalam penelitian ini data yang digunakan dibagi dua bagian.

Menurut Sunyoto (2016: 21), mengatakan bahwa "Data primer adalah data asli yang dikumpulkan sendiri oleh peneliti untuk menjawab masalah penelitiannya, sedangkan data sekunder adalah yang bersumber dari catatan yang ada pada tempat penelitian, dan dari sumber lainnya yaitu dengan mengadakan studi kepustakaan dengan mempelajari buku-buku yang ada hubungannya dengan objek penelitian”.

Berdasarkan pendapat di atas maka jenis data yang digunakan dalam penelitian ini adalah data primer dan data sekunder.

\section{Populasi}

Dalam penelitian memerlukan populasi sebagai objek penelitian. Menurut Sugiyono (2016: 80), mengatakan bahwa "Populasi adalah wilayah generalisasi yang terdiri atas obyek atau subyek yang mempunyai kuantitas dan karakteristik tertentu yang ditetapkan oleh peneliti untuk dipelajari dan kemudian ditarik kesimpulannya". 
Yang menjadi populasi dalam penelitian ini adalah pelanggan di Warung Makan TIP TOP Kelurahan Saombo Kecamatan Gunungsitoli Kota Gunungsitoli dihimpun dari bulan Januari s.d. bulan Desember 2020 selama 1 tahun berjumlah 966 orang.

\section{Sampel}

Sampel adalah sebagian dari jumlah dan karakteristik yang dimiliki oleh populasi tersebut, ataupun bagian kecil dari anggota populasi yang diambil menurut prosedur tertentu sehingga dapat mewakili populasinya. Jika populasi besar. Menurut Suharsimi Arikunto (2006: 134), bahwa apabila subjeknya kurang dari 100 orang, lebih baik di ambil semua sehingga penelitiannya merupakan penelitian populasi. Tetapi, jika jumlah subjeknya besar, dapat diambil antara $10-15 \%$ atau $20-25 \%$ atau lebih.

Mengingat jumlah subjeknya lebih dari 100 orang, maka dengan demikian sampel penelitian yang digunakan penulis adalah pelanggan selama 1 tahun di Warung Makan TIP TOP Kelurahan Saombo Kecamatan Gunungsitoli Kota Gunungsitoli sebesar 10\% x 966 = 96,6 dibulatkan menjadi 97 orang.

\section{HASIL PENELITIAN Pengujian Alat Penelitian Uji Validitas}

Untuk menguji apakah instrument yang dipakai cukup layak digunakan sehingga mampu menghasilkan data yang akurat sesuai dengan tujuan pengukurannya maka dilakukan uji validitas sebagaimana tabel di bawah ini:

Hasil Perhitungan Validitas untuk Variabel $\mathrm{X}$

\begin{tabular}{|c|c|c|c|c|c|c|c|c|}
\hline Butir Soal & $\sum \mathrm{X}$ & $\sum \mathrm{Y}$ & $\sum \mathrm{X}^{2}$ & $\sum \mathrm{Y}^{2}$ & $\sum \mathrm{XY}$ & $\mathrm{r}_{\text {hitung }}$ & $\mathrm{r}_{\text {tabel }}$ & Ket. \\
\hline 1 & 330 & 3.153 & 1.146 & 104.485 & 10.884 & 0,729 & 0,198 & Valid \\
\hline 2 & 320 & 3.153 & 1.100 & 104.485 & 10.631 & 0,771 & 0,198 & Valid \\
\hline 3 & 323 & 3.153 & 1.131 & 104.485 & 10.755 & 0,444 & 0,198 & Valid \\
\hline 4 & 322 & 3.153 & 1.102 & 104.485 & 10.604 & 0,534 & 0,198 & Valid \\
\hline 5 & 320 & 3.153 & 1.114 & 104.485 & 10.668 & 0,781 & 0,198 & Valid \\
\hline 6 & 332 & 3.153 & 1.170 & 104.485 & 10.937 & 0,695 & 0,198 & Valid \\
\hline 7 & 285 & 3.153 & 881 & 104.485 & 9.469 & 0,695 & 0,198 & Valid \\
\hline 8 & 316 & 3.153 & 1.070 & 104.485 & 10.437 & 0,581 & 0,198 & Valid \\
\hline 9 & 285 & 3.153 & 881 & 104.485 & 9469 & 0,695 & 0,198 & Valid \\
\hline 10 & 320 & 3.153 & 1.100 & 104.485 & 10.631 & 0,773 & 0,198 & Valid \\
\hline \multicolumn{8}{|c|}{ Sumber : Angket diolah oleh penulis }
\end{tabular}

Hasil Perhitungan Validitas untuk Variabel $Y$

\begin{tabular}{|c|c|c|c|c|c|c|c|c|}
\hline Butir Soal & $\sum \mathrm{X}$ & $\sum \mathrm{Y}$ & $\sum \mathrm{X}^{2}$ & $\sum \mathrm{Y}^{2}$ & $\sum \mathrm{XY}$ & $\mathrm{r}_{\text {hitung }}$ & $\mathrm{r}_{\text {tabel }}$ & Ket. \\
\hline 1 & 331 & 3.103 & 1.153 & 101.095 & 10.730 & 0,682 & 0,198 & Valid \\
\hline 2 & 309 & 3.103 & 1.023 & 101.095 & 10.987 & 0,760 & 0,198 & Valid \\
\hline 3 & 305 & 3.103 & 1.013 & 101.095 & 10.008 & 0,799 & 0,198 & Valid \\
\hline 4 & 314 & 3.103 & 1.054 & 101.095 & 10.197 & 0,581 & 0,198 & Valid \\
\hline 5 & 315 & 3.103 & 1.075 & 101.095 & 10.323 & 0,798 & 0,198 & Valid \\
\hline 6 & 335 & 3.103 & 1.191 & 101.095 & 10.839 & 0,490 & 0,198 & Valid \\
\hline 7 & 281 & 3.103 & 851 & 101.095 & 9.170 & 0,718 & 0,198 & Valid \\
\hline 8 & 316 & 3.103 & 1.072 & 101.095 & 10.324 & 0,771 & 0,198 & Valid \\
\hline 9 & 284 & 3.103 & 866 & 101.095 & 9.266 & 0,720 & 0,198 & Valid \\
\hline 10 & 316 & 3.103 & 1.072 & 101.095 & 10.324 & 0,771 & 0,198 & Valid \\
\hline
\end{tabular}

Sumber : Angket diolah oleh penulis

\section{Uji Reliabilitas}

Uji Reliabilitas digunakan untuk menguji sejauh mana keandalan suatu alat pengukur untuk dapat digunakan dalam penelitian ini. Pengujian reliabilitas dalam penelitian ini adalah dengan menggunakan metode pembelahan ganjil genap.

Diperoleh $\mathrm{N}=97, \sum \mathrm{X}=1.543, \sum \mathrm{Y}=1.610, \sum \mathrm{X}^{2}=25.313, \sum \mathrm{Y}^{2}=27.308, \sum \mathrm{XY}=25.932$. Hasil yang telah diperoleh disubtitusikan ke dalam rumus korelasi product moment, yang dijabarkan sebagai berikut: 


$$
\begin{aligned}
& r_{x y}=\frac{N\left(\sum x y\right)-\left(\sum x\right)\left(\sum y\right)}{\sqrt{\left\{N \sum x^{2}-\left(\sum x\right)^{2}\right\}\left\{N \sum y^{2}-\left(\sum y\right)^{2}\right.}} \\
& r_{x y}=\frac{97(25.932)-(1.543)(1.610)}{\sqrt{\left\{97(25.313)-(1.543)^{2}\right\}\left\{97(27.308)-(1.610)^{2}\right.}} \\
& r_{x y}=\frac{2.515 .404-2.484 .230}{\sqrt{\{2.455 .361-2.380 .849\}\{2.648 .876-2.592 .100\}}} \\
& r_{x y}=\frac{31.174}{\sqrt{\{74.512\}\{56.776\}}} \\
& r_{x y}=\frac{31.174}{\sqrt{4.230 .493,312}} \\
& r_{x y}=\frac{31.174}{65.042 .242,519} \\
& r_{x y}=0,479
\end{aligned}
$$

Setelah didapat koefisien reliabilitas dengan pembelahan ganjil genap pada variabel $\mathrm{X}$, selanjutnya dihitung reliabilitas dengan menggunakan rumus Spearman Brown sebagai berikut:

$$
\begin{aligned}
& r_{11}=\frac{2 \cdot r_{1 / 21 / 2}}{1+r_{1 / 21 / 2}} \\
& r_{11}=\frac{2 \times 0,479}{1+0,479} \\
& r_{11}=\frac{1.958}{1,479} \\
& r_{11}=0,648
\end{aligned}
$$

Di dapatkan nilai $\mathrm{r}_{11}=0,648>\mathrm{r}_{\text {tabel }}=0,198$ dan kriteria harga $\mathrm{r}$ adalah tinggi maka dapat disimpulkan bahwa tes pada variabel X tersebut secara keseluruhan telah reliabel dan dapat digunakan sebagai tes pada penelitian.

Kemudian untuk variable $\mathrm{Y}$ diperoleh $\mathrm{N}=97, \sum \mathrm{X}=1.232, \sum \mathrm{Y}=1.274, \sum \mathrm{X}^{2}=16.088, \sum \mathrm{Y}^{2}=17.070$, $\sum X Y=16.431$. Hasil yang telah diperoleh disubtitusikan ke dalam rumus korelasi product moment, yang dijabarkan sebagai berikut:

$$
\begin{aligned}
r_{x y} & =\frac{N\left(\sum x y\right)-\left(\sum x\right)\left(\sum y\right)}{\sqrt{\left\{N \sum x^{2}-\left(\sum x\right)^{2}\right\}\left\{N \sum y^{2}-\left(\sum y\right)^{2}\right.}} \\
r_{x y} & =\frac{97(16.431)-(1.232)(1.274)}{\sqrt{\left\{97(16.088)-(1.232)^{2}\right\}\left\{97(17.070)-(1.274)^{2}\right.}} \\
r_{x y} & =\frac{1.593 .807-1.569 .568}{\sqrt{\{1.560 .536-1.519 .824\}\{1.655 .790-1.623 .076\}}} \\
r_{x y} & =\frac{24.239}{\sqrt{\{42.712\}\{32.714\}}} \\
r_{x y} & =\frac{24.239}{\sqrt{1.397 .280 .368}} \\
r_{x y} & =\frac{24.239}{37.380 .213,589} \\
r_{x y} & =0,648
\end{aligned}
$$

Setelah didapat koefisien reliabilitas dengan pembelahan ganjil genap pada variabel $\mathrm{Y}$, selanjutnya dihitung reliabilitas dengan menggunakan rumus Spearman Brown sebagai berikut:

$$
r_{11}=\frac{2 \cdot r_{1 / 21 / 2}}{1+r_{1 / 21 / 2}}
$$




$$
\begin{aligned}
r_{11} & =\frac{2 \times 0,648}{1+0,648} \quad \text { dengan } \mathrm{dk}=\mathrm{n}-2 \\
r_{11} & =\frac{1.296}{1.648} \\
r_{11} & =0,786
\end{aligned}
$$

Di dapatkan nilai $r_{11}=0,786>r_{\text {tabel }}=0,198$ dan kriteria harga $r$ adalah tinggi maka dapat disimpulkan bahwa tes pada variabel Y tersebut secara keseluruhan telah reliabel dan dapat digunakan sebagai tes pada penelitian.

\section{Uji Koefisien Korelasi}

Untuk mengetahui korelasi antara variabel $\mathrm{X}$ dengan Varibel $\mathrm{Y}$ dilakukan dengan menggunakan rumus korelasi product moment yang data-datanya sebagai berikut:

Berdasarkan disajikan diperoleh $\mathrm{N}=97, \sum \mathrm{X}=3.153, \sum \mathrm{Y}=3.103, \sum \mathrm{X}^{2}=104.485, \sum \mathrm{Y}^{2}=101.095$, $\sum X Y=102.273$. Hasil yang telah diperoleh disubtitusikan ke dalam rumus korelasi product moment, yang dijabarkan sebagai berikut:

$$
\begin{aligned}
r_{x y} & =\frac{N\left(\sum x y\right)-\left(\sum x\right)\left(\sum y\right)}{\sqrt{\left\{N \sum x^{2}-\left(\sum x\right)^{2}\right\}\left\{N \sum y^{2}-\left(\sum y\right)^{2}\right.}} \\
r_{x y} & =\frac{97(102.273)-(3.153)(3.103)}{\sqrt{\left\{97(104.485)-(3.153)^{2}\right\}\left\{97(101.095)-(3.103)^{2}\right.}} \\
r_{x y} & =\frac{9.920 .481-9.783 .759}{\sqrt{\{1.135 .045-9.941 .409\}\{9.806 .215-9.628 .609\}}} \\
r_{x y} & =\frac{136.722}{\sqrt{\{193.636\}\{177.606\}}} \\
r_{x y} & =\frac{136.722}{\sqrt{34.390 .915 .416}} \\
r_{x y} & =\frac{136.722}{185.447 .877,895} \\
r_{x y} & =0,737
\end{aligned}
$$

Dari harga $r_{\text {kritik }}$ pada taraf signifikan 5\% dengan jumlah $\mathrm{N}=97$, diperoleh $\mathrm{r}_{\text {tabel }}=0,198$. Dengan demikian harga $r_{\text {hitung }}>r_{\text {tabel }}(0,737>0,198)$, maka dapat dikatakan terdapat pengaruh yang signifikan antara variabel X (Marketing Mix) dengan Y (Loyalitas Pelanggan).

\section{Uji Koefisien Determinan}

Berdasarkan hasil perhitungan nilai korelasi antara variabel X dengan Y dapat dihitung seberapa besar persentase yang dapat dijelaskan variabel bebas terhadap variabel terikat dengan menggunakan rumus:

$$
\begin{aligned}
& \mathrm{KD}=\left(\mathrm{r}^{2}\right) \times 100 \% \\
& \mathrm{KD}=(0,737)^{2} \times 100 \% \\
& \mathrm{KD}=0,543 \times 100 \% \\
& \mathrm{KD}=54 \%
\end{aligned}
$$

\section{Regresi Linear Sederhana}

Berdasarkan data yang diperoleh perhitungan korelasi antara Marketing Mix terhadap Loyalitas Pelanggan di distribusikan ke dalam rumus regresi linear sederhana untuk memprediksikan seberapa tinggi nilai variabel $X$ terhadap variable $Y$, maka di dapatkan hasil sebagai berikut: $Y=9,04+0,67 x$

\section{Uji Hipotesis (Uji $t)$} berikut:

Selanjutnya dalam tahapan pengujian hipotesis, penulis menggunakan uji $t$ dengan persamaan sebagai

$$
t=\frac{r_{y 1} \sqrt{(N-2)}}{\sqrt{1-r_{y 1}^{2}}}
$$




$$
\begin{aligned}
& t=\frac{0,737 \sqrt{(97-2)}}{\sqrt{1-0,737^{2}}} \\
& t=\frac{0,737 \sqrt{(95)}}{\sqrt{1-0,543}} \\
& t=\frac{(0,737)(9,746,794)}{0.676,017} \\
& t=\frac{7.183 .387,178}{0,676,017} \\
& t=10.626
\end{aligned}
$$

Daftar distribusi $t$ dengan $\mathrm{dk}=95$ dan taraf signifikan 5\% diperoleh $\mathrm{t}_{\text {tabel }}=1.661$. Dengan demikian bahwa $t_{\text {hitung }}>t_{\text {tabel }}(10.626>1.661)$, sehingga dapat disimpulkan bahwa terdapat pengaruh positif dan signifikan antara variabel X (marketing mix) dengan variabel Y (loyalitas pelanggan), maka $\mathbf{H}_{\mathbf{0}}$ di tolak dan $\mathrm{H}_{\mathbf{a}}$ diterima.

\section{Analisis Hasil Penelitian}

Marketing Mix merupakan strategi yang dipergunakan oleh perusahaan dalam mempengaruhi permintaan atas produk kepada pelanggan sehingga pelanggan tidak mudah meninggalkan produk dari perusahaan dan tetap melakukan pembelian terhadap produk yang ditawarkannya.

Pemasaran merupakan salah satu kegiatan yang dilakukan oleh perusahaan dalam usaha mencapai tujuan perusahaan yaitu mempertahankan kelangsungan hidup dan mendapatkan laba yang maksimum. Berhasil tidaknya mencapai tujuan tersebut tergantung dari keahlian mereka di bidang pemasaran, produksi dan bidang-bidang lain yang menunjang tercapainya tujuan tersebut.

Loyalitas (loyalty) sebagai komitmen yang dipegang secara mendalam untuk membeli atau mendukung kembali produk atau jasa yang disukai di masa depan meski pengaruh situasi dan usaha pemasarn berpotensi menyebabkan pelanggan beralih.

Dari hasil analisis penelitian yang dilaksanakan di Warung Makan TIP TOP Kelurahan Saombo Kecamatan Gunungsitoli Kota Gunungsitoli dapat di kemukakan bahwa:

1. Hasil perhitungan uji validitas butir item angket variabel X (Marketing Mix) dan variabel Y (Loyalitas Pelanggan) dinyatakan memenuhi syarat validitas dimana $r_{\text {hitung }}>r_{\text {tabel }}$, yaitu untuk variabel $X$ Nomor 1 $(0,729>0,198)$ dan untuk variabel Y Nomor $1(0,682>0,198)$.

2. Hasil perhitungan uji reliabilitas marketing mix memperoleh nilai sebesar 0,648 dan untuk loyalitas pelanggan memperoleh nilai sebesar 0,786 , dimana variabel $X(0,648>0,198)$ dan untuk variabel $\mathrm{Y}(0,786>0,198)$.

3. Hasil perhitungan koefisien korelasi antara variabel X (Marketing Mix) dengan variabel Y (Loyalitas Pelanggan) menunjukkan bahwa tabel $r_{\text {kritik }}$ pada taraf signifikan 5\% dengan jumlah $\mathrm{N}=95$, diperoleh $\mathrm{r}_{\text {hitung }}=0,737$, dan $\mathrm{r}_{\text {tabel }}=0,198$.

Dengan demikian harga $\mathrm{r}_{\text {hitung }}>\mathrm{r}_{\text {tabel }}(0,737>0,198)$, maka dapat dikatakan terdapat pengaruh yang signifikan antara variabel $\mathrm{X}$ dengan variabel $\mathrm{Y}$.

4. Hasil perhitungan koefisien determinasi nilai korelasi antara varibel X (Maketing Mix) dengan variabel $\mathrm{Y}$ (Loyalitas Pelanggan) menggunakan rumus $\mathrm{KD}=\left(\mathrm{r}^{2}\right) \times 100 \%$, maka diperoleh nilai sebesar $54 \%$.

5. Hasil pengujian regresi liniar sederhana diperoleh persamaan $Y=9.04+0,67 x$.

6. Hasil perhitungan uji hipotesis $t$ dengan $\mathrm{dk}=\mathrm{n}-2=97-2=95$ pada taraf signifikan $5 \%$ dengan tingkat kepercayaan $95 \%$ diperoleh $t_{\text {hitung }}=10.661$ dan $\mathrm{t}_{\text {tabel }}=1.661$, sehingga dapat dikatakan bahwa terdapat pengaruh antara variabel X (Marketing Mix) dengan variabel Y (Loyalitas Pelanggan), sehingga $\mathbf{H}_{\mathbf{o}}$ di tolak dan $\mathrm{H}_{\mathrm{a}}$ diterima.

7. Untuk variabel bebas yaitu marketing mix terbukti memiliki pengaruh positif dan signifikan terhadap loyalitas pelanggan di Warung Makan TIP TOP Kelurahan Saombo Kecamatan Gunungsitoli Kota Gunungsitoli.

\section{KESIMPULAN DAN SARAN}

\section{A. KESIMPULAN}

Berdasarkan hasil penelitian yang telah dilakukan di Warung Makan TIP TIP Kelurahan Saombo Kecamatan Gunungsitoli Kota Gunungsitoli, maka selanjutnya penulis menyampaikan kesimpulan sebagai berikut: 
1. Marketing Mix di Warung Makan TIP TOP Kelurahan Saombo Kecamatan Gunungsitoli Kota Gunungsitoli, memiliki pengaruh yang positif dan signifikan terhadap Loyalitas Pelanggan berdasarkan perhitungan koefisien korelasi sebesar 0,737, Sehingga $r_{\text {hitung }}>r_{\text {tabel }}(0,737>0.198)$.

2. Pengaruh marketing mix terhadap loyalitas pelanggan di Warung makan TIP TOP Kelurahan Saombo Kecamatan Gunungsitoli Kota Gunungsitoli, dari hasil pengolahan data, dan hasil perhitungan koefisien determinasi maka diperoleh kesimpulan sebagai berikut:

a. Hasil pengolahan data distribusi $t$ dengan $\mathrm{dk}=95$ dan taraf signifikan $5 \%$ diperoleh $\mathrm{t}_{\text {tabel }}=1.661$. Dengan demikian bahwa $t_{\text {hitung }}>t_{\text {tabel }}(10.626>1.661)$.

b. Hasil angket yang diolah dengan koefisien determinasi sebesar 54\% pengaruh marketing mix terhadap loyalitas pelanggan, sedangkan faktor-faktor lain yang tidak dibahas dalam penelitian ini sebesar $46 \%$.

3. Hasil pengujian hipotesis ternyata Ha diterima dan Ho ditolak, sebab $t_{\text {hitung }}>t_{\text {tabel }}(10.626>1.661)$, sehingga dapat dikatakan ada pengaruh positif antara marketing mix terhadap loyalitas pelanggan di Warung Makan TIP TOP Kelurahan Saombo Kecamatan Gunungsitoli Kota Gunungsitoli.

\section{B. SARAN}

Berkenaan dengan loyalitas pelanggan dalam kaitannya marketing mix dengan variabel yang mempengaruhinya, ada beberapa hal yang perlu mendapat perhatian, antara lain:

a. Marketing Mix di Warung Makan TIP TOP Kelurahan Saombo Kecamatan Gunungsitoli Kota Gunungsitoli, perlu ditingkatkan karena unsur yang sangat penting dalam setiap usaha warung makan adalah meraih kepercayaan para konsumen supaya tetap loyal dan datang kembali sehingga mereka sulit untuk melupakan.

Hal ini perlu ditegaskan karena hasil penelitian membuktikan bahwa marketing mix mempunyai pengaruh positif terhadap loyalitas pelanggan.

b. Perlu diadakan penelitian lebih lanjut tentang marketing mix terhadap loyalitas pelanggan guna memperluas hasil penelitian.

\section{DAFTAR PUSTAKA}

Arikunto, Suharsimi, 2006. Prosedur Penelitian. Suatu Pendekatan Pratik, Revisi. Penerbit RINEKA CIPTA, Jakarta

Charffey,2009. Manajemen Pemasaran Modern. Edisi Kedua. Yogyakarta: Liberty.

Kotler, P., \& Amstrong, G. (2001). Prinsip-prinsip Pemasaran Jilid 1 (edisi 12) Jakarta: Erlangga.

Kotler, Philip \& Keller, 2000. Manajemen Pemasaran. Edisi Milenium. Jilid ketiga. Jakarta: Indeks.

Kotler Philip, 2009, Manajemen Pemasaran di Indonesia, Analisis Perencanaan, Implementasi dan Pengendalian, Salemba Empat, Jaktarta.

Kotler, Philip. 2002. Manajemen Pemasaran. PT Prenhalindo, Jakarta

Kartajaya Hermawan, 2006, Marketing Mix, Bandung: Mizan Pustaka.

Sugiyono, 2010. Metode Penelitian Kuantitatif Kualitatif dan R\&D. Penerbit Alfa Beta, Bandung. ------,2016. Metode Penelitian Kuantitatif Kualitatif dan R\&D. Penerbit Alfa Beta, Bandung.

Sunyoto Dadang, 2016. Metodologi Penelitian Akuntansi, Cetakan Kedua. Maret 2016. Penerbit PT. Refika Aditama, Bandung 40254.

Swastha, Basu, 2000. Azas-azas Marketing. Penerbit Liberty, Yogyakarta

Tjiptono, Fandy, 2007. Pemasaran Jasa. Edisi Ketiga, Penerbit Bayumedia Publishing, Malang ------, 2008. Pemasaran Jasa. Edisi Empat, Penerbit Bayumedia Publishing, Malang

------, 2010. Strategi Pemasaran. Yogyakarta: Andi Offset. 